\title{
THE PRICE TRANSMISSION IN EUROPEAN STOCK MARKEIS
}

\section{YALAN FNG ${ }^{*}$, J AMES RANK REFALO2}

1. Califomia State University Los Angeles, USA

* Corresponding Author: Yalan Feng, Department of Finance, Law and Real Esta te, College of Business and Ec onomics, Califomia State University Los Angeles, 5151 State University Drive, Los Angeles, CA 90032, USA $\varangle$ yfeng10@ca Istatela.edu

\begin{abstract}
We investigate the dynamic price relationships among ten major stock ind exes in Europe before, during and a fter the recent financial crisis. Using an error-correction model we find that the stock markets are cointegrated with three cointegrating vectors before the crisis and only one cointegrating vector during and after the crisis. We further use directed acyclic graph (DAG) analysis to explore the instantaneous transmission pattem. Contrary to previous research, the UK market is consistently mapped as being caused by several other markets, and France and Spain appear to share leadership roles before the crisis, while lea dership is less evident during and post crisis. We a lso find a decreasing number of instantaneous casual relationships between the markets after the crisis, indicating that the markets are becoming more independent. This result is corroborated by a decline in the number of cointegrating vectors from pre to post crisis.
\end{abstract}

Keywords: errorcorrection model (ECM), cointegration, directed acyclic graphs (DAG), fina ncial crisis

\section{Introduction}

Several studies in the financial literature have investigated market linkages and price transmission mechanisms in the major intemational equity markets, employing the a nalytic al fra mework of the vector a uto-regression (VAR) or the error correction model (ECM). However, virtually all of these models rely on some form of temporal causa lity. Yang and Bessler (2004) extended the literature by using the method of directed acyclic graphs (DAGs) in combination with emor correction modelling to explore evidence of contemporaneous causal pattems in intemational equity ma rket data.

This paper extends this literature by adopting the tec hniques in Bessler and Yang (2004) to provide evidence of structural change in stock market linkages and price transmission in response to the 2007-2012 fina ncial c risis. We first divide post-2000 weekly stock index data from ten prominent European markets into three periods representing pre-crisis (2000-2006), crisis (2007-2012), and post-crisis (2013-2016). We then evaluate price transmission between these markets duning these three periods using an errorcorrection model to compute an innovation correlation matrix for each period and corresponding DAG and compare the results. 
The paper is organized as follows. Section 2 provides data and summary statistics. Section 3 disc usses methodology. Section 4 explains the empirical results of our error correction modelling and DAG analysis. Section 5 presents the conclusions.

\section{Data}

We use weekly time series for ten European equity indexes in local currency terms (Belgium: BEL 20, France: CAC 40, Germa ny: DAX, G reece: ASE, Irela nd: ISEQ, Italy: FISE MIB, Netherlands: AEX, Spain: IBEX 35, Switzerland: SMI, and the UK: FISE 100), from J anua ry 2000 to May 2016 (857 observations for each index). All indic es a re rescaled to start at 100 at the beginning of the period. Figure 1 depicts weekly time series for the ten indices. All markets experienced a substantial run-up prior to 2007, and precipitous decline during financial crisis through 2012. Beginning 2012, all markets (with the exception of Greece and Italy), participated in a recovery, with the Geman index showing the strongest upward trend. Table 1 provides the corresponding summary statistic s. Note that Ireland's ma rket exhibits the greatest volatility, and Greece exhib its the worst performance (pre and post crisis).

\section{Figure 1: Index Performance 2000-2016}

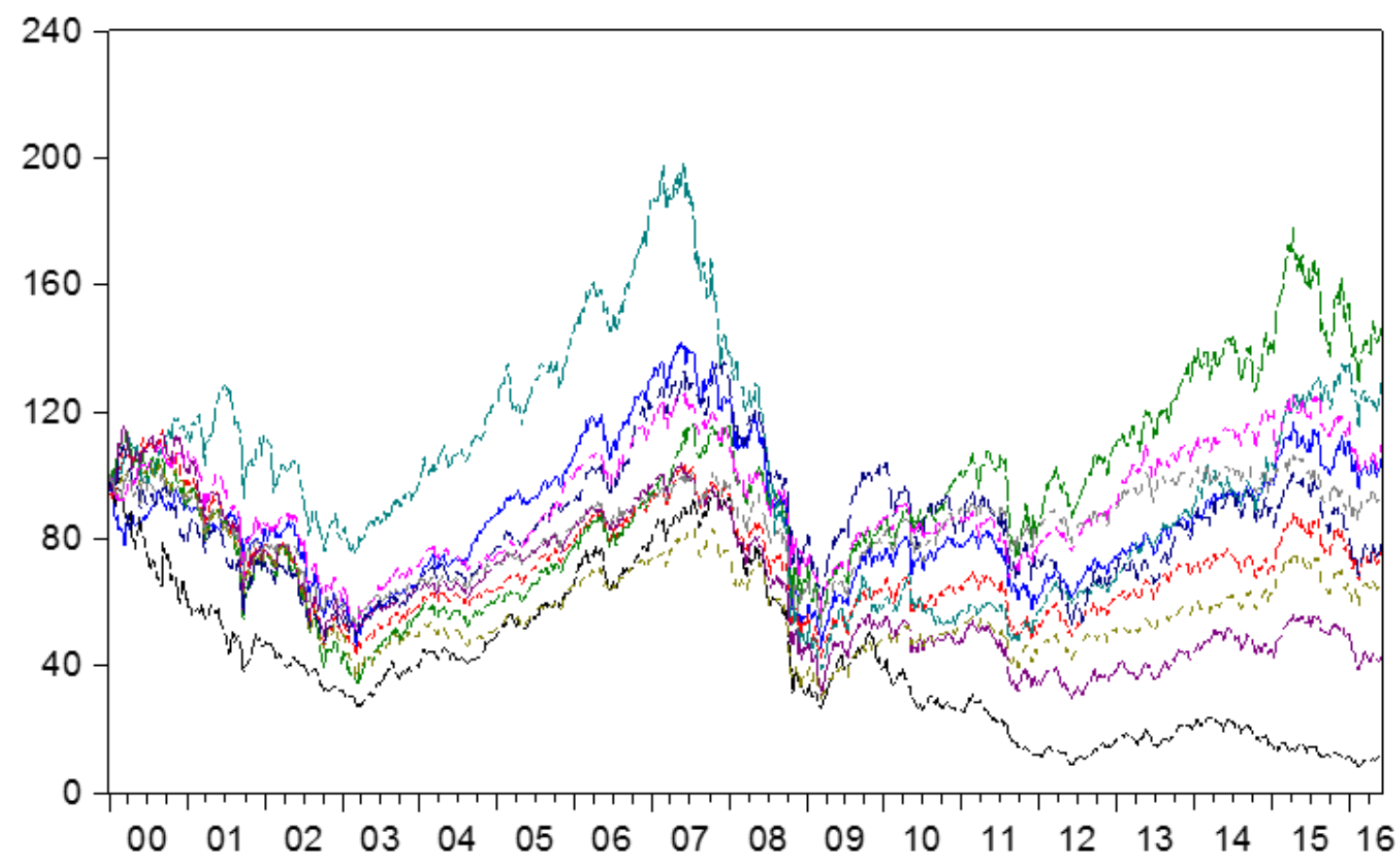

\begin{tabular}{|lll|}
\hline- BELGIUM & ---- FRANCE & --- GERMANY \\
-- GREECE & --- IRELAND & -- ITALY \\
--- NETHERLANDS & --- SPAIN & --- SWITZERLAND \\
--- UK & & \\
\hline
\end{tabular}


Table 1:Summary statistics. All indexes are rescaled to start with 100 at the beginning of J anuary 2000

\begin{tabular}{lcccccccccc}
\hline & BE & R & DE & GR & IE & T & NL & ES & CH & UK \\
\hline Mean & 86.8 & 71.9 & 92.7 & 41.8 & 100.9 & 63.8 & 60.9 & 84.6 & 92.1 & 83.9 \\
Median & 83.6 & 69.9 & 89.7 & 38.8 & 99.7 & 56.1 & 57.9 & 83.4 & 90.0 & 86.2 \\
Max & 142.2 & 114.4 & 177.8 & 100.0 & 198.6 & 115.8 & 103.5 & 135.9 & 125.9 & 106.4 \\
Min & 45.7 & 42.5 & 34.5 & 8.2 & 38.9 & 29.9 & 29.7 & 47.2 & 51.3 & 52.4 \\
Strdev & 20.6 & 15.6 & 30.4 & 24.0 & 35.5 & 21.7 & 15.8 & 18.8 & 17.4 & 12.9 \\
Skew & 0.6 & 0.6 & 0.5 & 0.5 & 0.5 & 0.6 & 0.8 & 0.6 & 0.0 & -0.5 \\
Kurt & 2.8 & 2.6 & 2.7 & 2.2 & 2.8 & 2.2 & 3.2 & 3.0 & 2.0 & 2.2 \\
\#Obs. & 857 & 857 & 857 & 857 & 857 & 857 & 857 & 857 & 857 & 857 \\
\hline Source: finance.Yahoo.com & & & & & & & & &
\end{tabular}

Source: finance.Yahoo.com

\section{Methodology}

\subsection{Emor Comection Modelling}

Following Yang and Bessler (2004) and Refalo (2009), we first apply a cointegrated VAR model to evaluate the data. Letting $X_{t}$ denote a vector of ten indexes $(\mathrm{k}=10)$, the corresponding vector ECM is specified as:

$$
\Delta X_{t}=\Pi X_{t-1}+\sum_{i=1}^{k-1} \Gamma_{i} \Delta X_{t-i}+\mu+\varepsilon_{t} \quad(t=1, \ldots, T)
$$

$$
\varepsilon_{t} \sim \operatorname{iid}(0, \Sigma)
$$

$\mu$ is a ( $k$ by 1 ) vector of intercepts, $\varepsilon$ t is the corresponding vector of white noise disturbance terms, and $\Gamma i$ are ( $k$ by $k$ ) coeffic ient matric es defining the short-run adjustments to changes in the price process. Of interest is evidence of a price transmission mechanism contributing to deviations in long-run relationships between market indexes. If the indexesare cointegrated, $\Pi$ can be factored into two matrices, $\Pi=\alpha \beta^{\prime}$, where $\beta$ is the cointegrating vector and a indicates the speed of adjustment to the previous period's deviation from the cointegrating relationship. The rank of $\Pi$ determines the number of cointegrating vectors.

We apply Trace tests developed by J ohansen (1991) to determine the number of cointegrating vectors. The test statistic s is computed as:

$$
\text { Trace }=-\sum_{i=r+1}^{k} \operatorname{Tln}\left(1-\lambda_{i}^{*}\right)
$$


where $\lambda_{i}^{*}$ are the estimated eigenvalue(s), $T$ is the number of observations, and $r$ is the maximum cointegrating rank. Rejection of the hypothesis implies the number of cointegrating vectors exc eeds $r$. In order for the cointegration test to be valid, unit root tests are conducted on each series to test for non-stationarity before we apply the cointegration test.

\subsection{Directed Acyclic Graphs}

The method of directed acyclic graphs (DAG) uses a series of logic based rules to deduce contempora neous causal relations from the correlation structure of a dataset. It is applied by first determining which variables a re un-conditionally or conditionally correlated, and then by using a series of logic arguments (known as sepset conditions) to determine causal direction of these correlations, creating a causal map linking the variables. The advantage of this method is that it requires no ad-hoc or theoretic al restric tions (though such restric tions may be employed) in determining links or causality. This paper uses TEIRAD 5.2.1 software for constructing the DAGs.

In our application, one begins with a diagram of the ten markets connected to each other by straight lines (links), each representing the correlation between those markets. Links between markets that a re not statistic ally correlated a re eliminated. The remaining links are then tumed into a rrows (using the sepset conditions in a stage known as orientation) indicating the causal direction of correlation. The resulting graph (or DAG) indicates the pattem of contemporaneous causality between the ten markets. Note that in this paper, we apply no exogenous or structural restric tions in detemining our DAGs, and elimina te all links that are not signific ant at the .01 level.

The method is extensively discussed in science literature in Spirtes et al (2000) and Glymour and Cooper (1999). DAG has been applied to studying financial data in a number of other papers including Bessler and Yang (2003), Yang and Bessler (2004), Haigh et al (2004), a nd Li et al (2008), and Refa lo (2009). The latter two papers provide a detailed overview of the algorithm ( $L$ et al 2008 illustrate how the algorithm works graphically). More recently J ayech (2011) studies the August 2011 stock market cra sh with a DAG-copula based approach using daily retums of stock indic es and bonds.

\section{Empirical analysis}

\subsection{Emor Comection Modelling and Cointegration Tests}

Table 2 presents results from Johansen cointegration tests. The tests are conducted without a drift tem in the VAR; all tests assume a constant in the cointegrating vector(s). Testing is ended at the first failure to reject the hypothesis; the Akaike information criterion was used to select the number of VAR lags used (one for pre-crisis period and two for crisis and post-crisis periods). The results are three cointegrating vectors linking the markets in the pre-crisis period, and only one cointegrating vector linking the markets crisis and postcrisis, indicating reduced market cointegration after the crisis began. The cointegrating ranks we observe are consistent with Bessler and Yang (2003) which notes that stock price series tend to exhib it fewer cointegrating vectors, indic ating a loose long-run co-movement a mong stock ma rket prices. Likewise, intema tional equity market studies using cash indices by Francis and Leachman 
(1998) and Masih and Masih (2001) find only one (or no) cointegrating vector linking the markets. ${ }^{1}$

\section{Table 2: Johansen's Cointegration Tests}

Reported are the Trace test statistics, under a hypothesis $\mathrm{HO}$ of zero to three cointegrating vectors. Where Tis the number of observations, $r$ is the maximum number of cointegrating vectors, $n$ is the number of eigenvalues, and $\lambda^{*}$ is the estimated eigenvalue, the statistics are given by Equation (3). Results displayed are for the three sub-sample periods 2000-2006, 2007-2012 and 2013-2016.2

\begin{tabular}{l|ccc|ccc|ccc}
\hline & \multicolumn{3}{c|}{$2000-2006$} & \multicolumn{3}{c|}{ 2007-2012 } & \multicolumn{3}{c}{ 2013-2016 } \\
\hline & \multicolumn{3}{c}{ VAR lag=1 } & \multicolumn{3}{c}{ VAR lag =2 } & \multicolumn{3}{c}{ VAR lag =2 } \\
\hline H0 rank & Trace & C(5\%) & Decision & Trace & C(5\%) & Decision & Trace & C(5\%) & Decision \\
\hline None & 345.6 & 251.3 & $\mathrm{R}$ & 253.9 & 251.3 & $\mathrm{R}$ & 263.1 & 251.3 & $\mathrm{R}$ \\
Atmost 1 & 249.4 & 208.4 & $\mathrm{R}$ & 190.7 & 208.4 & $\mathrm{~F}$ & 181.5 & 208.4 & $\mathrm{~F}$ \\
Atmost 2 & 177.8 & 169.6 & $\mathrm{R}$ & 150.6 & 169.6 & $\mathrm{~F}$ & 131.8 & 169.6 & $\mathrm{~F}$ \\
Atmost3 & 132.4 & 134.7 & $\mathrm{~F}$ & 113.2 & 134.7 & $\mathrm{~F}$ & 98.3 & 134.7 & $\mathrm{~F}$ \\
\hline
\end{tabular}

\subsection{Emor Comection Modelling and Cointegration Tests}

The ECM yields the innovation correlation matrices (4.1-4.4), with the markets listed in the order Belg ium, France, Gemany, Greece, Ireland, Ita ly, Netherlands, Spain, Switzerland, and UK, for pre-crisis, crisis, post-crisis, and all periods combined:

$$
\begin{aligned}
& \Sigma_{\text {precrisis }}=\left[\begin{array}{cccccccccccc}
1 & & & & & & & & & \\
0.66 & 1 & & & & & & & & \\
0.67 & 0.89 & 1 & & & & & & & \\
0.32 & 0.41 & 0.39 & 1 & & & & & & \\
0.58 & 0.58 & 0.60 & 0.25 & 1 & & & & & \\
0.66 & 0.87 & 0.85 & 0.38 & 0.57 & 1 & & & & \\
0.76 & 0.89 & 0.87 & 0.40 & 0.60 & 0.86 & 1 & & & \\
0.63 & 0.80 & 0.79 & 0.38 & 0.53 & 0.78 & 0.77 & 1 & & \\
0.76 & 0.72 & 0.71 & 0.30 & 0.56 & 0.72 & 0.79 & .64 & 1 & \\
0.68 & 0.84 & 0.81 & 0.31 & 0.57 & 0.79 & 0.83 & 0.72 & 0.76 & 1
\end{array}\right] \\
& \Sigma_{\text {crisis }}=\left[\begin{array}{cccccccccccc}
1 & & & & & & & & & \\
0.90 & 1 & & & & & & & & \\
0.82 & 0.92 & 1 & & & & & & & \\
0.70 & 0.67 & 0.60 & 1 & & & & & & \\
0.74 & 0.72 & 0.65 & 0.59 & 1 & & & & & \\
0.87 & 0.93 & 0.84 & 0.67 & 0.67 & 1 & & & & \\
0.90 & 0.93 & 0.87 & 0.68 & 0.72 & 0.86 & 1 & & & \\
0.79 & 0.87 & 0.81 & 0.63 & 0.59 & 0.86 & 0.78 & 1 & & \\
0.83 & 0.87 & 0.81 & 0.60 & 0.70 & 0.83 & 0.85 & 0.75 & 1 & \\
0.86 & 0.93 & 0.89 & 0.63 & 0.70 & 0.86 & 0.91 & 0.79 & 0.86 & 1
\end{array}\right]
\end{aligned}
$$

\footnotetext{
${ }^{1}$ We also test whether each price series is itself stationary and conduct additional tests for the restric tions on the cointegration space.

2 J ohansen's cointegration tests are also performed with the whole sample 2000-2016. Trace test indic a tes two cointegrating equations at the 0.05 level with two VAR lags.
} 


$$
\Sigma_{\text {postcrisis }}=\left[\begin{array}{ccccccccccc}
1 & & & & & & & & & \\
0.92 & 1 & & & & & & & & \\
0.89 & 0.92 & 1 & & & & & & \\
0.39 & 0.41 & 0.37 & 1 & & & & & & \\
0.73 & 0.74 & 0.72 & 0.38 & 1 & & & & & \\
0.80 & 0.85 & 0.79 & 0.56 & 0.66 & 1 & & & & \\
0.89 & 0.94 & 0.90 & 0.39 & 0.73 & 0.82 & 1 & & & \\
0.80 & 0.86 & 0.78 & 0.54 & 0.60 & 0.88 & 0.82 & 1 & & \\
0.64 & 0.62 & 0.61 & 0.25 & 0.51 & 0.50 & 0.62 & 0.56 & 1 & \\
0.76 & 0.82 & 0.77 & 0.34 & 0.58 & 0.70 & 0.84 & 0.70 & 0.65 & 1
\end{array}\right]
$$

$$
\Sigma_{\text {all }}=\left[\begin{array}{ccccccccccc}
1 & & & & & & & & & \\
0.81 & 1 & & & & & & & & \\
0.77 & 0.89 & 1 & & & & & & & \\
0.50 & 0.51 & 0.43 & 1 & & & & & & \\
0.68 & 0.66 & 0.61 & 0.43 & 1 & & & & & \\
0.76 & 0.89 & 0.78 & 0.50 & 0.61 & 1 & & & & \\
0.83 & 0.91 & 0.83 & 0.49 & 0.65 & 0.85 & 1 & & & \\
0.75 & 0.83 & 0.78 & 0.51 & 0.59 & 0.82 & 0.76 & 1 & & \\
0.76 & 0.76 & 0.72 & 0.42 & 0.60 & 0.71 & 0.76 & 0.68 & 1 & \\
0.79 & 0.86 & 0.81 & 0.45 & 0.62 & 0.78 & 0.84 & 0.75 & 0.78 & 1
\end{array}\right]
$$

Unconditionally the correlations between countries a re similar in magnitude to the results of Yang and Bessler (2004), which uses country stock future index data. This result is unsurprising given the degree of economic integration among markets in this study.

Dividing the data into pre-crisis, crisis, and post-crisis periods, we find that the instantaneous correlations are greater during the crisis period. To test the signific ance of thischange in correlation between periods, we employ the Z-test with the Fisher transformation, Fisher (1921). First, we transform each correlation coeffic ient using Equation (5):

$$
\rho^{\prime}=0.5 \ln \left(\frac{1+\rho}{1-\rho}\right)
$$

We then test for statistical signific ance in the difference in correlation for each element of the innovation correlation matrix between any two periods by computing the z-statistic and corresponding $\mathrm{p}$-value:

$$
Z=\frac{\rho_{1}^{\prime}-\rho_{2}^{\prime}}{\sqrt{\frac{1}{N_{1}-3}+\frac{1}{N_{2}-3}}}
$$


Matrices 7.1-7.3 display changes in the correlation coeffic ients from pre-crisis to crisis, crisis to post-crisis, and pre-crisis to post-crisis, which a re signific ant at the $5 \%$ significance level. A 1 for an increase, -1 for a decrease, and 0 for no statistic ally signific ant change:

$$
\begin{aligned}
& \Sigma_{\text {crisis }}-\sum_{\text {precrisis }}=\left[\begin{array}{ccccccccccc}
N A & & & & & & & & & \\
1 & N A & & & & & & & & \\
1 & 1 & N A & & & & & & & \\
1 & 1 & 1 & N A & & & & & & \\
1 & 1 & 0 & 1 & N A & & & & & \\
1 & 1 & 0 & 1 & 1 & N A & & & & \\
1 & 1 & 0 & 1 & 1 & 0 & N A & & & \\
1 & 1 & 0 & 1 & 0 & 1 & 0 & N A & & \\
1 & 1 & 1 & 1 & 1 & 1 & 1 & 1 & N A & \\
1 & 1 & 1 & 1 & 1 & 1 & 1 & 1 & 1 & N A
\end{array}\right] \\
& \Sigma_{\text {postcrisis }}-\Sigma_{\text {crisis }}=\left[\begin{array}{cccccccccccc}
N A & & & & & & & & & \\
0 & N A & & & & & & & & \\
1 & 0 & N A & & & & & & & \\
-1 & -1 & -1 & N A & & & & & & \\
0 & 0 & 0 & -1 & N A & & & & & \\
-1 & -1 & 0 & 0 & 0 & N A & & & & \\
0 & 0 & 0 & -1 & 0 & 0 & N A & & & \\
0 & 0 & 0 & 0 & 0 & 0 & 0 & N A & & \\
-1 & -1 & -1 & -1 & -1 & -1 & -1 & -1 & N A & \\
-1 & -1 & -1 & -1 & -1 & -1 & -1 & -1 & -1 & N A
\end{array}\right] \\
& \Sigma_{\text {postcrisis }}-\Sigma_{\text {precrisis }}=\left[\begin{array}{cccccccccccc}
N A & & & & & & & & & \\
1 & N A & & & & & & & & \\
1 & 0 & N A & & & & & & & \\
0 & 0 & 0 & N A & & & & & & \\
1 & 1 & 1 & 0 & N A & & & & & \\
1 & 0 & -1 & 1 & 0 & N A & & & & \\
1 & 1 & 0 & 0 & 1 & 0 & N A & & & \\
1 & 1 & 0 & 1 & 0 & 1 & 0 & N A & & \\
-1 & 0 & 0 & 0 & 0 & -1 & -1 & 0 & N A & \\
0 & 0 & 0 & 0 & 0 & -1 & 0 & 0 & -1 & N A
\end{array}\right]
\end{aligned}
$$

Compared with pre-crisis levels, 38 out of 45 correlation coefficients are statistic ally greater during the crisis. The majority of the correlation coefficients then decrease following the crisis. Comparing pre-crisis and post crisis pa irwise correlations, the Belgian, Irish, and Greek markets generally exhibit greater correlation with the othermarkets post-crisis, and the Swiss and UK markets show evidence of reduced post-crisis pa inwise correlation. 


\subsection{DAG Analysis}

To study evidence of instantaneous casualty and structural changes in the pattem of causality for pre-crisis, crisis, and post-crisis periods, we construct DAGs for the innovation correlation matrices 4.1-4.4, respectively. As disc ussed in section 3.2, all graphs are estimated requiring a .01 significance level for correlation between markets.

Figure $2 \mathrm{~A}$ presents the DAG for the pre-crisis period. There are ten directional links (including one bidirectional link) and five non-directional links. The graph indicates a direct causal flow from France, Germany, and Switzerland to the UK, with Netherlandsand Spa in causing UK indirec tly via Gemany. This result differs from Yang and Bessler (2004), which finds the UK to have a leadership role among the European markets. The difference in findings may be due to the different data span (1997-2007 vs 2000-2006), frequency of the data (daily vs weekly), instrument (index future vs index), and the number of European countries examined in our studies (four versus ten). France and Spain are graphed ashaving leadership roles. OurDAG also revealschanges in the Italian market to be driven by trading in several other markets. There a re links between Switzerland, Netherlands, Belgium, and Ireland, but in general, there is little evidence of a directional causa lity pattem among those markets.

That Germany is mapped as being caused by several lesser markets may be explained by the one to three hour delay in closing times of the German Exchanges (19:00 and 21:00 UTC) vis-a-vis the other European exchanges, allowing for additional trading in the Geman market in response to last minute tra des in markets that have closed. Our results a re consistent with an integrated market prior to the financial crisis - with many market indices moving simultaneously in response to contemporaneous information, and the difference in market closing times explaining why the Geman index is graphed as a follower. Also note that $\mathrm{G}$ reece, the nation which will laterface a sovereign debt crisis in 2009, is shown as an outlier in the pre-crisis period, not having a ny casual flow to or from other countries.

Figure 2B presents the DAG for the crisis period 2007-2012 and has a different struc ture. Most countries have casual flows to and/or from other countries. The UK market is influenced directly by Germany, Netherlands, France, and Switzerland. Ireland and Greek markets a re now part of the causal diagram as being influenced directly or indirectly by trading in virtually all other markets. France has direct links with six markets, though only one causal relationship is mapped - France causing UK. During this period, the Geman and Netherlands markets a re graphed as having leadership roles. The diagram is consistent with centralized govemment (EU) policy changes and trading in quality markets driving the markets that a re in crisis. It is a lso consistent with investor flight to quality, where the markets in grea test crisis become followers.

Figure 2C presents the DAG for post-crisis period 2013-2016. Only two directional links and seven non-directional links are found. Again, UK is graphed as being caused by the other markets, and France has the greatest number of direct relationships. The Ireland index is graphed as having no causal flow with the other European markets, possibly reflecting that continued domestic policy tumoil has the greatest influence on trading in that market. The reduction in linkagesfrom pre-crisismay ind ic a te a greater degree of independence a mong these markets and could be the result of reforms implemented a fter the crisis to reduce risk taking and financial contagion. However, the presence of mostly 
non-directional links indicates simultaneous price movements and market integration.

Comparing the DAGs for the three periods, we find evidence consistent with centralized govemment policy making and investor flight to qua lity influencing the pattem of price information transmission during the crisis, and greater ma rket independence ex-post the crisis, using a contempora neous time a nalysis. This is consistent with VAR model analysis in which the number of cointegrating vectors in the data declined from three vectors pre-crisis to one post-crisis.

Figure 4D presents a DAG a nalysis for the entire sample (2000-2016). While there a re a number of bidirec tional relationships, what stand sout is that the UK ma rket is graphed as being caused by the other key markets. This is consistent with the results of our pre-crisis, crisis, and post-crisis gra phs.

\section{Figure 2A: Pre-Crisis Pattem from TEIRADV}

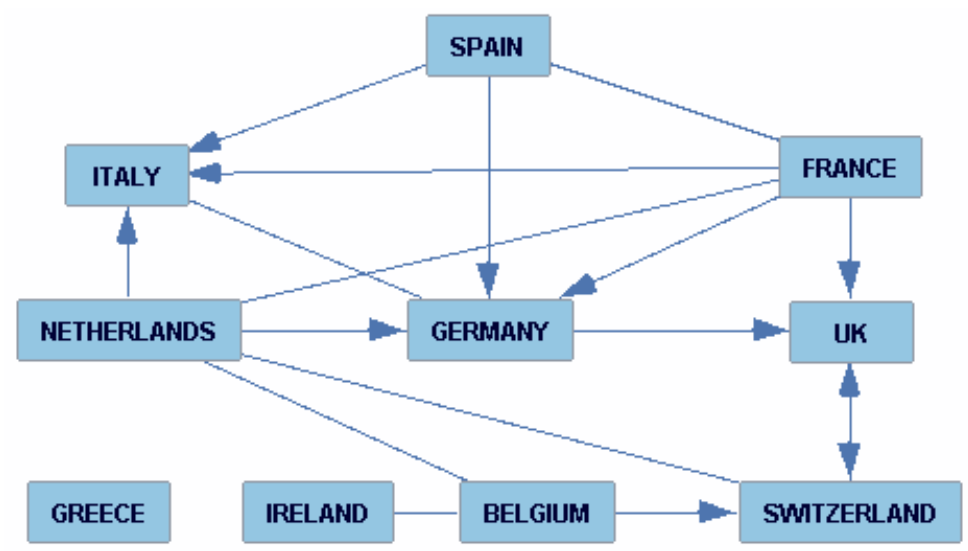

Figure 2B: Crisis Pattem from TEIRADV

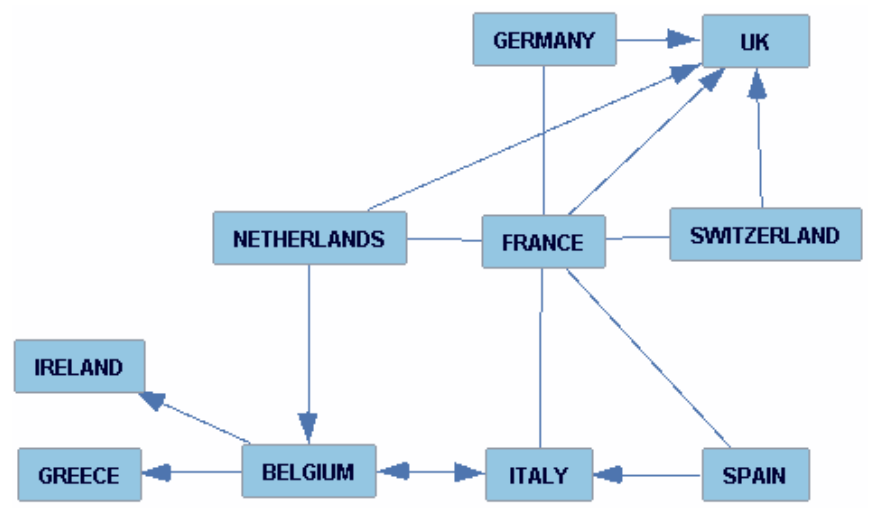


Figure 2C: Post-Crisis Pattem from TEIRAD V

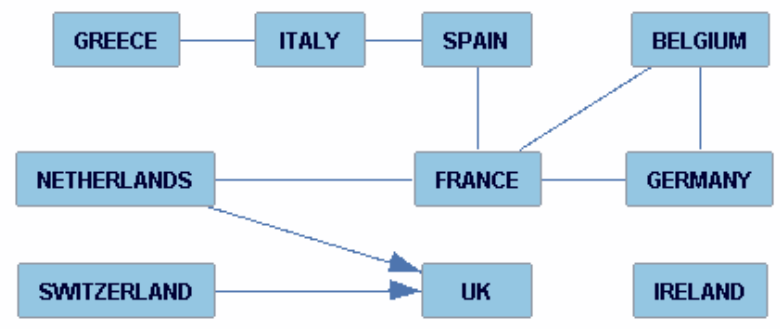

Figure 2D: Whole Sample Pattem from TEIRAD V

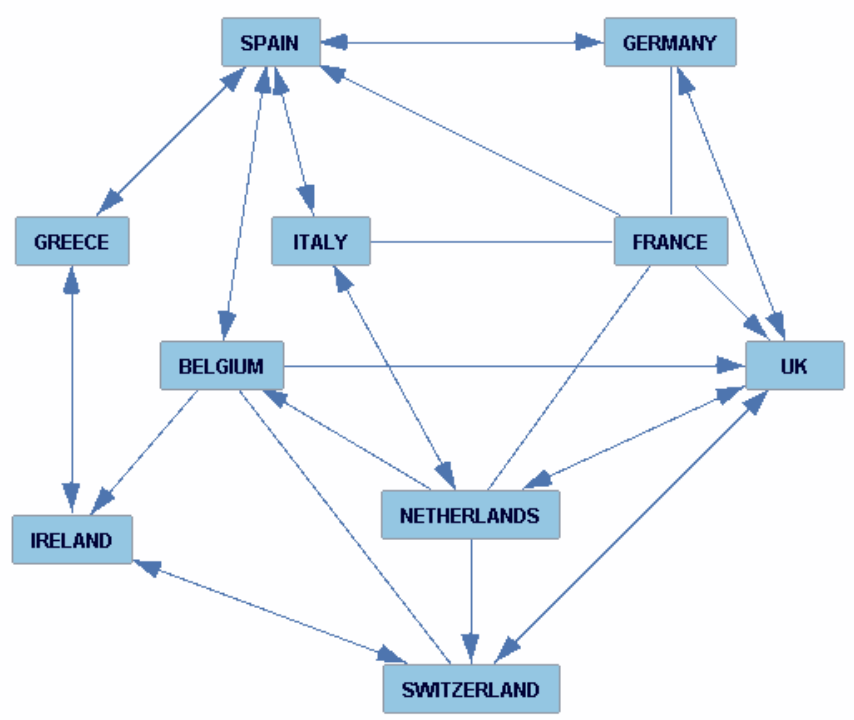

\section{Conclusion}

We investigate price transmission pattems in the ten European stock indexes before, during, and after the Great Recession following the approach of Yang and Bessler (2004), which combines cointegration, ECM, and DAG methodologies. Different from recent studies such as Francis and Leachman (1998), Masih and Masih (2001), and Bessler and Yang (2003), where only one cointegrating vector is found among major stock markets, and from Yang and Bessler (2004) where two cointegrating vectors are found, our ECM analysis indicates that there are three cointegrating before the crisis and only one cointegrating vector in the other periods.

We then study instanta neous ca usa lity between these ma rkets using DAGs. France and Spa in a ppearto share lea dership roles before the crisis while Germany and Netherlands become leaders during the crisis. Contrary to previous research, the UK is consistently graphed as being caused by other markets (though this becomes more pronounced during the crisis), and the Irish and Greek market indices are graphed as being caused by other market indic es during the crisis period. We also find a decrease in the number of instantaneous casual links between the markets after the crisis, with most links bec oming non-directional, indic ating greater independence of the European markets. This result is consistent with the results of our VAR model, and may be a result of post- 
crisis regulatory reforms to reduce risk taking and potential financial contagion in response to the stock market meltdowns. The impact of reform mechanisms on the European market linkages (and trading) is a sweeping topic that deserves extensive research but is beyond the scope of this paper.

\section{References}

Bessler, D. A., J. Yang and M. Wongcharupan (2003). "Price Dynamics in the Intemational Wheat Market: Modeling with Error Correction and Directed Acyclic Graphs."J oumal of Regional Science 43(1): 1-33.

Fisher, R. A. (1921). "On the 'probable emor' of a coeffic ient of correlation deduced from a small sample". Metron. 1: 3-32.

Francis, B., and L. Leachman. "Superexogeneity and the Dynamic Linkages among Intemational Equity Markets."J oumal of Intemationa I Money and Fina nce, 17, 1998, 47592.

Glymour, C., and Cooper, G. (1999). Computation, Ca usation, and Disc overy. MITPress, Cambridge, MA.

J ohansen, S. "Estimation and Hypothesis Testing of Cointegration vectors in Gaussian Vector Autoregressive Models." Econometrica, 59, 1991, 1551-80.

Haigh M. S., Nomikos, N. K., and Bessler, D. A. (2004). Integration and causality in the intemational freight markets: modelling with error correction and directed acyclic graphs. Southem Economic J oumal 71, 145-162.

L, G., J. F. Refalo and L. Wu (2008). "Causality-in-Variance and Causality-in-Mean among European Govemment Bond Markets." Applied Financial Ec onomics 18(19-21): 1709-1720.

Jayech, S. (2011) The contagion channels of J uly-August-2011 stock market crash: A DAG-copula based approach, European Joumal of Operational Research, Volume 249, Issue 2, 1 March 2016, Pages 631-646.

Masih, R., and A. M. M. Masih. "Long and Short Term Dynamic Causal Transmission a mongst Intemational Stock Markets."J oumal of Intemational Money and Finance, 20, 2001, 563-87.

Refa lo, J . F. (2009). "China's Impact on Price Shocks in the World Oil Markets."J oumal of Energy Markets 2(1): 89-113.

Spirtes, P., C. Glymour and R. Scheines (2000). Causation, prediction, and search, Sec ond edition.

Yang, J. and D. A. Bessler (2004). "The Intemational Price Transmission in Stock Index Futures Markets." Ec onomic Inquiry 42(3): 370-386. 